INTEGRATIVE LITERATURE REVIEWS AND META-ANALYSES

\title{
Living with early-stage dementia: a review of qualitative studies
}

\author{
Els Steeman MSc RN \\ PhD Student, Center for Health Services and Nursing Research, Faculty of Medicine, Katholieke Universiteit Leuven, Leuven, \\ Belgium; and Assistant Academic Staff Member, Department of Nursing Science, Faculty of Medicine, Ghent University, Gent, \\ Belgium
}

\author{
Bernadette Dierckx de Casterlé PhD RN \\ Associate Professor, Center for Health Services and Nursing Research, Faculty of Medicine, Katholieke Universiteit Leuven, \\ Leuven, Belgium
}

Jan Godderis MD PhD

Professor, Department of Neurosciences and Psychiatry, Faculty of Medicine, Katholieke Universiteit Leuven, Leuven, Belgium

Mieke Grypdonck PhD RN

Professor, Department of Nursing Science, Faculty of Medicine, Ghent University, Gent, Belgium; and Professor, Department of Nursing Science, Julius Centre for Health Sciences and Primary Care, University Medical Centre, Utrecht, The Netherlands

Accepted for publication 27 October 2005

\author{
Correspondence: \\ Els Steeman, \\ Department of Nursing Science, \\ Ghent University, \\ UZ Blok A, \\ De Pintelaan 185 , \\ B - 9000 Gent, \\ Belgium. \\ E-mail:els.steeman@ugent.be
}

STEEMAN E., DE CASTERlÉ B.D., GODDERIS J. \& GRYPDONCK M. (2006) Journal of Advanced Nursing 54(6), 722-738

Living with early-stage dementia: a review of qualitative studies

Aim. This paper presents a literature review whose aim was to provide better understanding of living with early-stage dementia.

Background. Even in the early stages, dementia may challenge quality of life. Research on early-stage dementia is mainly in the domain of biomedical aetiology and pathology, providing little understanding of what it means to live with dementia. Knowledge of the lived experience of having dementia is important in order to focus pro-active care towards enhancing quality of life. Qualitative research is fundamentally well suited to obtaining an insider's view of living with early-stage dementia.

Method. We performed a meta-synthesis of qualitative research findings. We searched MEDLINE, CINAHL, and PsycINFO and reviewed the papers cited in the references of pertinent articles, the references cited in a recently published book on the subjective experience of dementia, one thesis, and the journal Dementia. Thirty-three pertinent articles were identified, representing 28 separate studies and 21 different research samples. Findings were coded, grouped, compared and integrated.

Findings. Living with dementia is described from the stage a person discovers the memory impairment, through the stage of being diagnosed with dementia, to that of the person's attempts to integrate the impairment into everyday life. Memory loss often threatens perceptions of security, autonomy and being a meaningful member of society. At early stages of memory loss, individuals use self-protecting and self-adjusting strategies to deal with perceived changes and threats. However, the memory impairment itself may make it difficult for an individual to deal with these changes, thereby causing frustration, uncertainty and fear. 
Conclusions. Our analysis supports the integration of proactive care into the diagnostic process, because even early-stage dementia may challenge quality of life. Moreover, this care should actively involve both the individual with dementia and their family so that both parties can adjust positively to living with dementia.

Keywords: early-stage dementia, human experience, life change events, literature review, meta-synthesis, nursing, qualitative research

\section{Introduction}

Although dementia can present in relatively young people, it is primarily a health problem of older people. With no cure in sight, dementia continues to be an invalidating chronic illness, affecting both the person with dementia and their immediate family. Because pharmacological treatment in the early stages can delay disease progression, more people are being diagnosed at earlier stages and are able to function better for longer periods before entering end-stage dementia.

In early-stage dementia, independent living is still possible but memory loss interferes with more complex activities of daily life (such as cooking, housekeeping, shopping and handling money), and especially with work and social activities (American Psychiatric Association 1987, World Health Organization 1993). As with any other chronic disease, early-stage dementia may affect quality of life for the individual with dementia and their family. Therefore, proactive care should begin early in the diagnostic process, with the aim of reducing excessive disability, dependency and suffering.

Given the reasonableness of such an approach, it is surprising that the research base for developing proactive care for these patients is limited. Research on early-stage dementia is mainly in the domain of biomedical aetiology and pathology. According to Kitwood (1990), however, dementia should be considered as a socially-embedded phenomenon, composed of interactions between the neurological impairment and life history, health status, personality and malignant social psychology. Gaining knowledge of the lived experience of having dementia, as a sociallyembedded phenomenon, is important in order to focus care towards enhancing quality of life for the individual with dementia, instead of towards treating the disease (Grypdonck 1996).

\section{Aim}

The aim of this review was to advance understanding of what a person experiences when trying to live with early-stage dementia. More specifically, we sought to advance understanding of the ways in which people with early-stage dementia come to understand, account for, take action, and otherwise manage their daily life with the condition (Miles \& Huberman 1994), and the ways in which social interaction is involved in this process.

\section{Search methods}

Quantitative research gives an outsider perspective on the phenomenon under study and explains by identifying determinants, while qualitative research explains by discovering and reconstructing processes from an insider perspective. Qualitative research is fundamentally wellsuited to studying the meanings people place on events in their lives and how these meanings are connected to the social world around them (Miles \& Huberman 1994). To obtain an insider's view of living with early-stage dementia, we carried out a meta-synthesis of qualitative studies of people with dementia. While a systematic review gives an overview of related studies, a meta-synthesis aims at an integrative interpretation of findings from single, related, qualitative studies to synthesize a more substantive description of the phenomenon (Sherwood 1999, Evans 2003, Fingeld 2003).

We searched MEDLINE, CINAHL and PsycINFO using the terms 'dement"' or 'Alzheimer"' and 'lived experience' or 'subjective experience'. Nesbit's CINAHL evidence-based filter for qualitative research was also used (Nesbit s.a.). We restricted the search to refereed publications in which the researchers interviewed people with early-stage dementia. Articles written in English or Dutch published between January 1990 and October 2004 were considered. 1990 was chosen as in the late 1980s a call was made to include the perspective of people with dementia in research and care (e.g. Lyman 1989), and this was expected to result in a rise in related research. To ensure an extensive search, we also manually searched the reference lists of all included articles, a recently published book on the subjective experience of dementia (Harris 2002), one thesis on early-stage dementia 
(Robinson 2000), and performed a focused search in the journal Dementia (Keady et al. 2002).

Studies meeting the inclusion criteria were appraised using Sandelowski and Barosso's (2002) guide for qualitative research. This guide helps to dissect and organize information in research reports in 13 categories: research problem, research purpose, literature review, orientation to the target phenomenon, method, sampling, sample, data collection, data management, validity, findings, discussion and ethics. It also facilitates appraisal of the physical format and reporting style. Appraisal parameters are offered to help judge how well or badly a category of information has been addressed and how relevant this is for the credibility of findings. The guide helped us to evaluate more systematically the informational adequacy, methodological rigour and flexibility, procedural and interpretative appropriateness, theoretical connectedness, heuristic relevance and descriptive vividness of the studies (Burns 1989, Popay et al. 1998, Sandelowski \& Barosso 2002, Eakin \& Mykhalovskiy 2003).

Of the 44 articles that met the inclusion criteria, 11 were deemed inappropriate according to our appraisal criteria. The studies of Keady et al. (1999a, 1999b), Husband (2000) and Marzanski (2000) were excluded because of methodological limitations. Keady et al. (1999a, 1999b) had no way of knowing how many of their telephone helpline callers really had dementia, which may have affected reliability of the findings. Husband's (2000) content analysis and frequency counts limited the amount of in-depth information on the lived experience, as did Marzanski's (2000) questionnaire study of patients' opinions of received and desired information about dementia. The study by Dabbs (1999) was excluded because of informational inadequacy regarding methodology. In Parse's study (Parse 1996) it was unclear if the Human Becoming Theory fit or was imposed on the data. In the papers by Aggarwal et al. (2003) and Beattie et al. (2004), findings on the experience of living with dementia were not well elaborated (limitations concerned heuristic relevance and theoretical connectedness). Norman et al. (2004) included people with moderate to severe dementia, whose perspective was scarcely represented in the study, and Proctor's (2001) and Reid et al.'s (2001) studies focused mainly on service evaluation from the perspective of people with dementia.

Thirty-three relevant articles were included, representing 28 separate studies and 21 different research samples. Table 1 summarizes the characteristics of the included studies. The majority of study participants were recruited through memory clinics and had a diagnosis of dementia, except for those in one sample in which people in the prediagnostic phase were included (Robinson et al. 1997, 1998, 2000b) and one person in another sample who had a diagnosis of cognitive impairment without dementia (Menne et al. 2002). Sample sizes ranged from 1 to 84 (median $=12$, IQR: 6-22), totalling 414 people with dementia. Some of these had cognitive impairment without dementia. However, because they might eventually develop dementia, they were included here. Both sexes were included, except for one study, which included only men (Pearce et al. 2002). The majority of studies included people younger than and older than 65 years of age. Three samples included only older people (Keady et al. 1995, Phinney 1998, 2002b, Keady \& Gilliard 2002, Keady \& Nolan 2003, Svanstrom \& Dahlberg 2004), and two samples included only younger people (Nygard \& Borell 1998, Robinson et al. 2000a). In 11 samples, the experiences of family caregivers were also surveyed. Table 1 summarizes the characteristics of the participants in all the studies we considered.

Geographically, nine samples were drawn from the United States of America, seven from the United Kingdom (UK), four from Sweden and one from Canada. The studies used descriptive, explorative, phenomenological, or grounded theory designs. While all generally explored the experience of living with dementia, some focused on specific aspects, such as the prediagnostic phase (Robinson et al. 1997, Keady \& Gilliard 2001), the assessment process (Keady \& Gilliard 2002), receiving a diagnosis (Robinson et al. 1998, 2000b, Pratt \& Wilkinson 2001), coping and adaptation (Clare 2002, Harris \& Durkin 2002, Pearce et al. 2002), identity (Harris \& Sterin 1999), occupational self (Nygard et al. 1995, Nygard \& Borell 1998), awareness of memory problems (Hutchinson et al. 1997, Robinson et al. 2000a, Phinney 2002a, Clare 2003), social interaction (Hutchinson et al. 1997, Snyder 2002, Keady \& Nolan 2003, Clare \& Shakespeare 2004, Svanstrom \& Dahlberg 2004) and the lived body (Phinney \& Chesla 2003).

Most studies were cross-sectional, with the exception of two three-year longitudinal case studies (Nygard \& Borell 1998, Robinson et al. 2000a).

We read the included publications several times, coded, grouped, compared the findings and integrated them along dimensions of time (prediagnostic, diagnostic, or postdiagnostic phase), experiences and meanings of memory loss, feelings related to memory loss, coping strategies and experiences of interactions with others.

\section{Findings}

All findings were sorted chronologically, from the prediagnostic phase through the diagnostic to the postdiagnostic phase. These three phases represent the transitional process. 


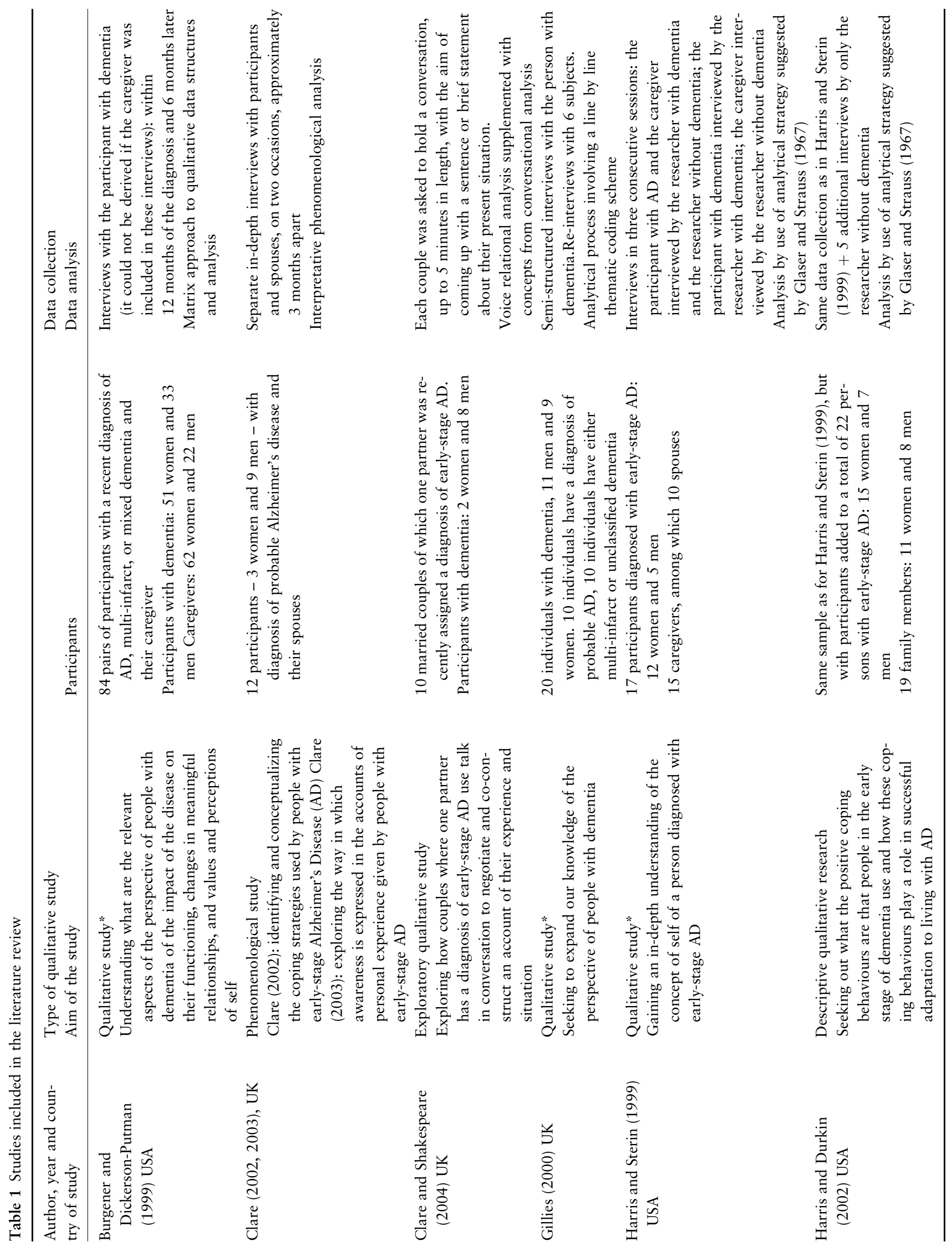




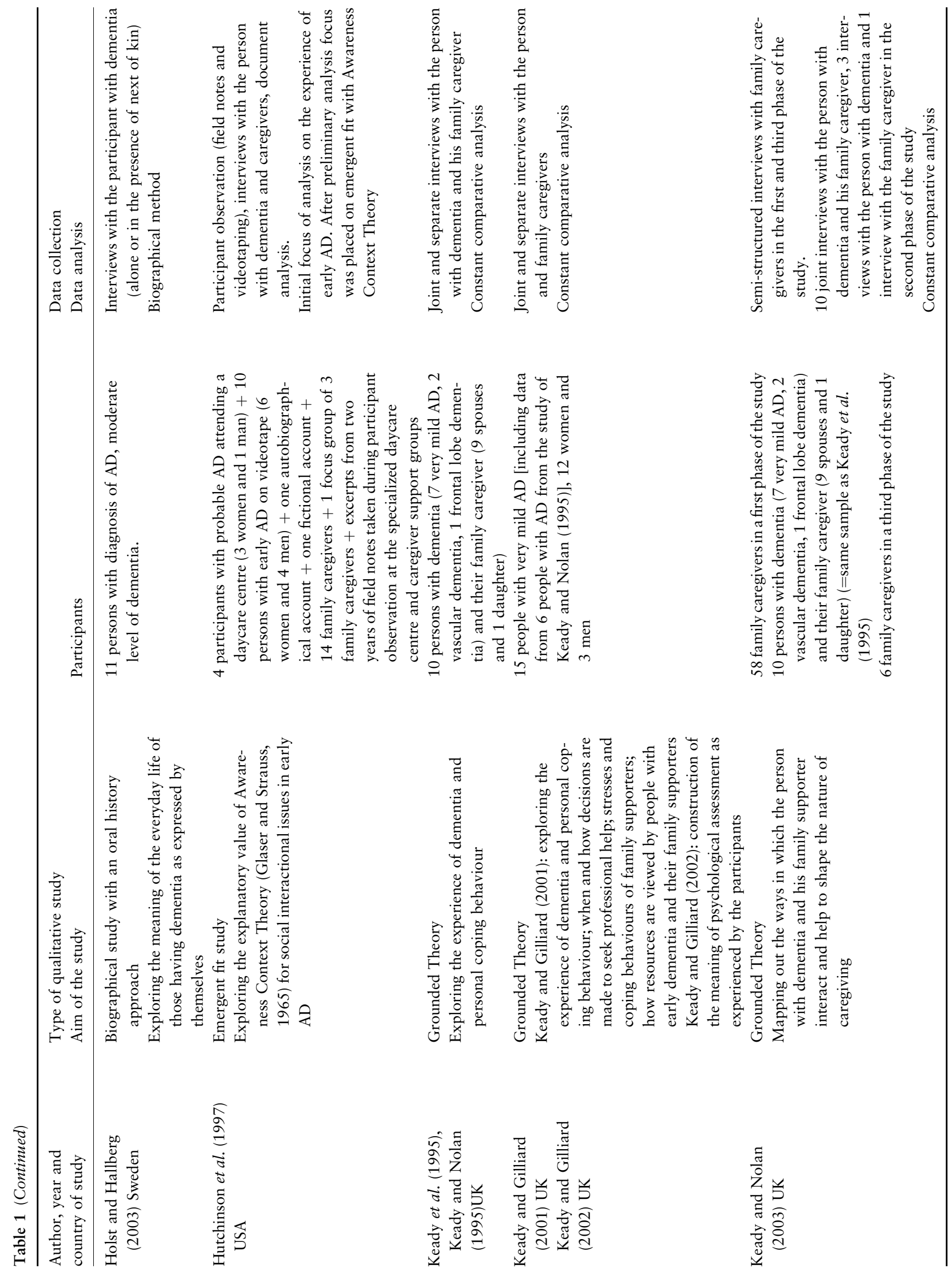




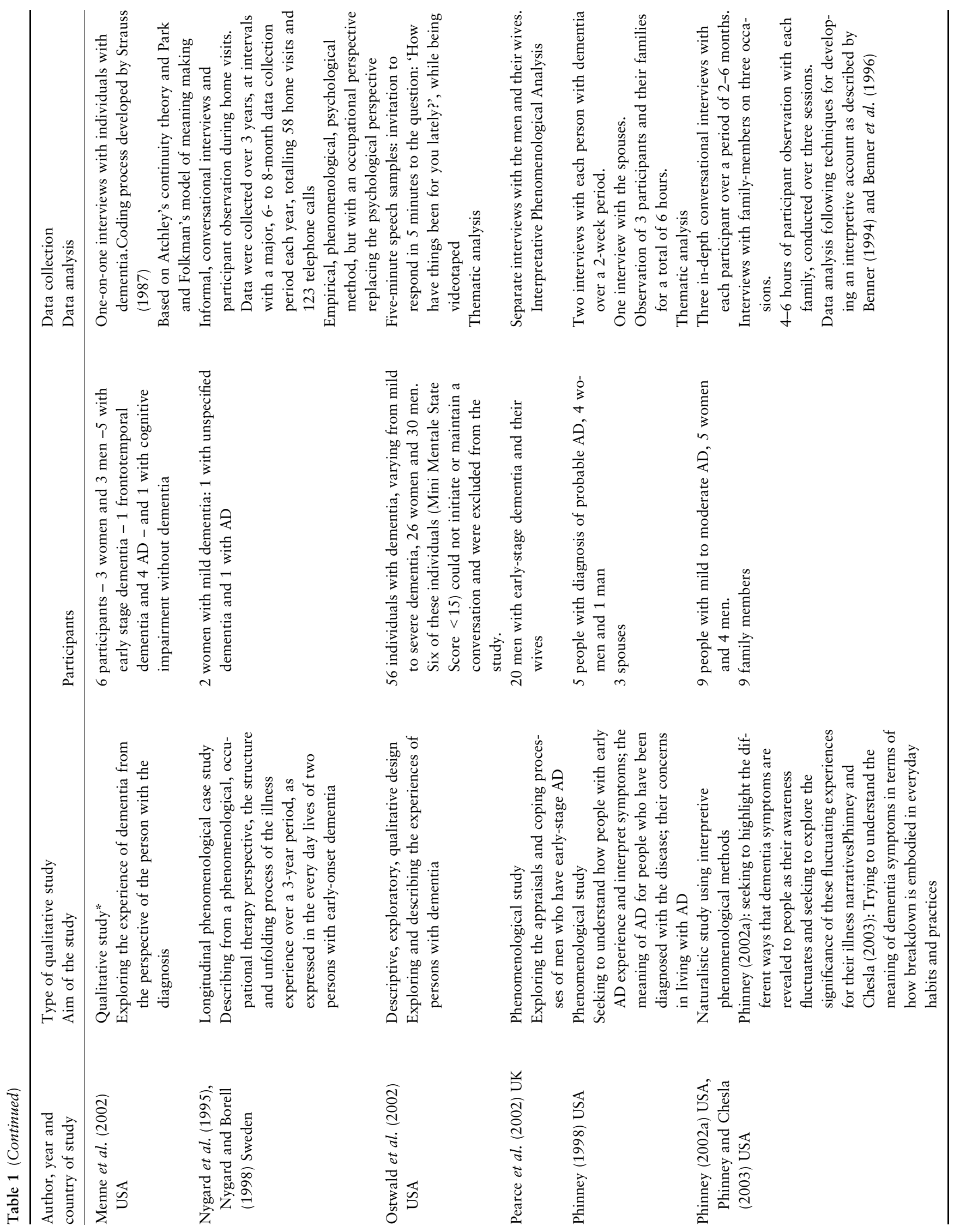




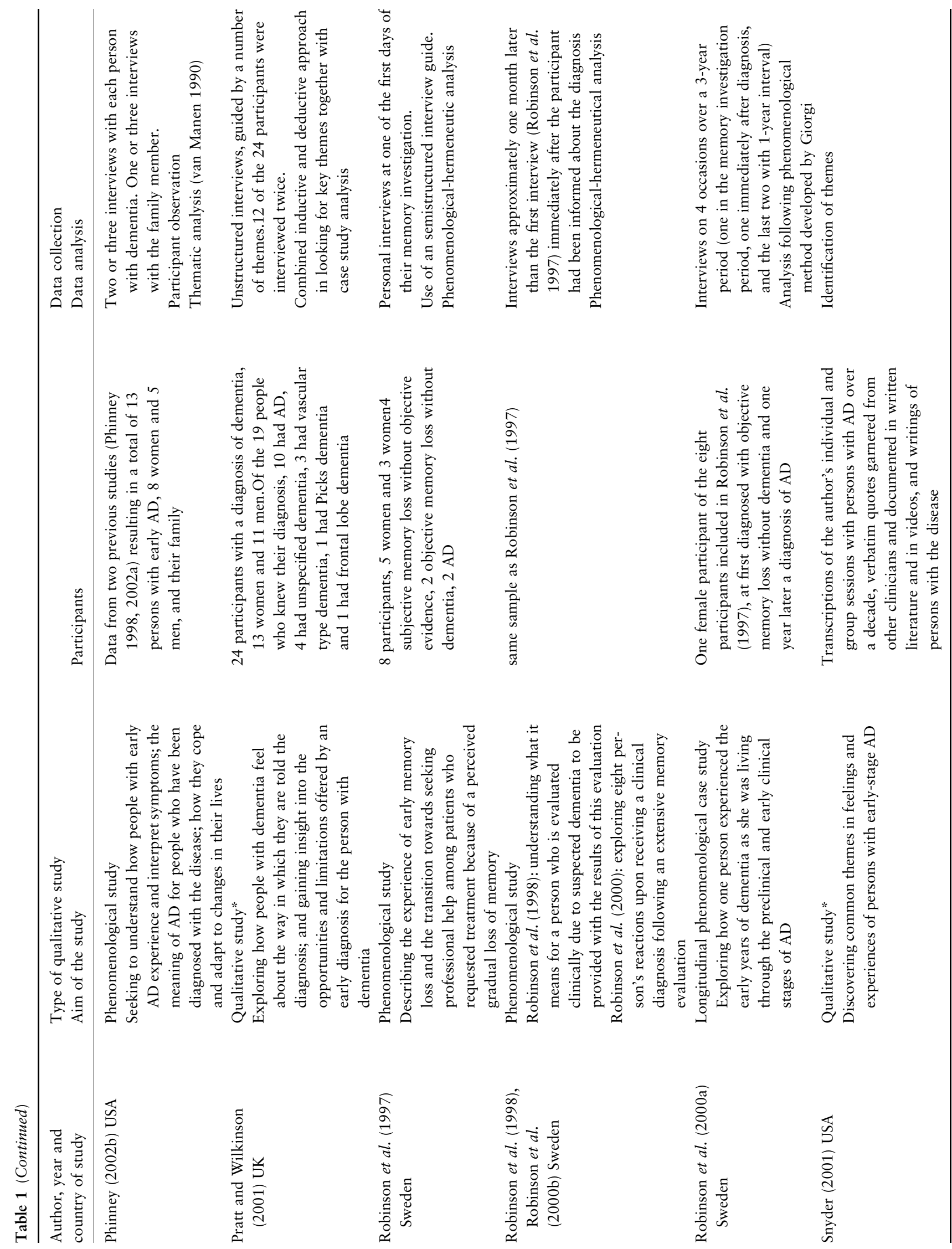




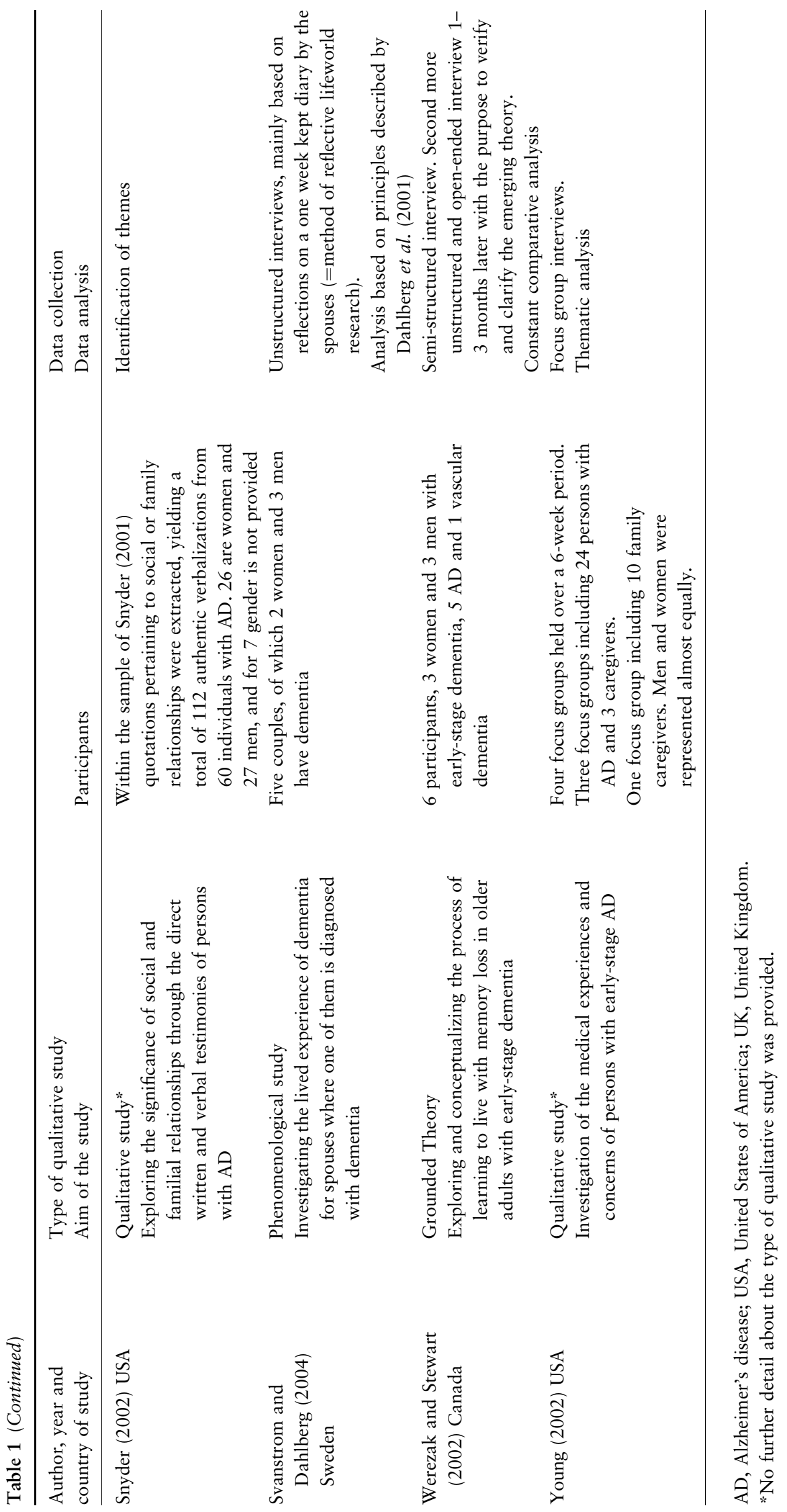




\section{The transitional process}

\section{Prediagnostic phase}

In general, the experience of living with dementia is presented in the literature as a highly individualized and complex process consisting of several progressive stages, starting long before diagnosis is or can be given. It is during this prediagnostic phase that affected people gradually become aware that they have a problem (Keady \& Nolan 1995, Robinson et al. 1997, Pratt \& Wilkinson 2001, Werezak \& Stewart 2002, Clare 2003, Keady \& Nolan 2003), initially passing off memory problems as part of normal ageing or as stress-related. As memory problems become more severe, they slowly suspect that something is very wrong (Keady \& Nolan 1995, Robinson et al. 1997, Clare 2003, Keady \& Nolan 2003). On the other hand, others may experience dramatic 'wake-up calls' when critical events happen, such as being banned from driving (Hutchinson et al. 1997). This typically forces them to admit that something is abnormal. Others may be unaware of their memory problems, yet are vaguely aware that something is wrong as other people repeatedly accuse them of forgetfulness (Robinson et al. 2000a, Phinney 2002a). In this latter case, discrepancy between accusations of forgetfulness and personal experience results in incomprehension, which is the basis of sensing that something is wrong (Robinson et al. 2000a).

Becoming aware that something is wrong produces frustration, uncertainty, and fear, which in turn puts stress on interpersonal relationships (Pratt \& Wilkinson 2001). These feelings stem from inability to understand the perceived changes and their unpredictability, lack of self-assurance and feelings of being out of control (Keady \& Nolan 1995, Keady et al. 1995, Robinson et al. 1997, 2000a, Pratt \& Wilkinson 2001).

Being aware that something is wrong also causes individuals with dementia to form strategies of watching and analysing themselves and others for signs of deterioration that eventually lead them to the stage of searching for meaning (Keady \& Nolan 1995, Robinson et al. 1997, Keady $\&$ Nolan 2003). Meanwhile, to maintain control and conceal growing memory problems, they develop strategies of vigilance and avoidance (Keady \& Nolan 1995, Robinson et al. 1997, 2000a).

Attempts to keep the problems hidden and to maintain the veneer of normality become increasingly difficult and cause psychological strain (Hutchinson et al. 1997, Robinson et al. 2000a, Keady \& Nolan 2003). Eventually, these strategies fail and close friends and family begin to notice the cognitive decline and may express their concern (Keady $\&$ Nolan 2003). In many cases, family members initiate the stage of sharing awareness (i.e. acknowledging the memory impairment), whereas in others the person with dementia does this (Keady \& Nolan 2003). The individual's desire to acknowledge the problem may be triggered by several needs: the need for an explanation (Robinson et al. 1997), the need to relieve the pressure of maintaining a normal appearance, and the need to feel supported (Keady \& Nolan 1995, Robinson et al. 2000a, Keady \& Gilliard 2001).

Sharing awareness may be limited to close family and friends (Hutchinson et al. 1997, Keady \& Nolan 2003). However, sharing awareness cannot be taken for granted. While disclosure of memory problems may relieve an individual with dementia, family members may not always be willing to acknowledge that their loved one has a problem (Keady \& Nolan 1995, Keady \& Gilliard 2001, Keady \& Nolan 2003). If this occurs, the individual may become frustrated, being uncertain as to what to do next (Keady \& Nolan 1995, Keady \& Gilliard 2001). Alternatively, people with dementia may not necessarily communicate the problem to their families (Clare 2003). This does not necessarily mean that they are unaware of having memory problems, nor that, by acknowledging the problem, they are fully aware of having memory problems. Alternately denying and acknowledging memory loss, or acknowledging memory loss without being able to describe it or without expressing concern or understanding may occur (Hutchinson et al. 1997). Awareness may eventually lead to the stage of seeking professional help.

\section{Diagnostic phase}

During the diagnostic phase, people who suspect that they have dementia seek help, have a neuropsychological assessment, and be diagnosed. It is important that professional caregivers take these individuals and their families seriously and respond with the necessary knowledge and skills to meet their needs (Keady \& Gilliard 2002). Being taken seriously may bring relief but also fear. Referral for neuropsychological testing may reinforce for these people the seriousness of their condition (Keady \& Gilliard 2002). From the time when they first seek help until the time when they receive the diagnosis, they may envisage or ponder over the diagnosis, their reaction to this, possible causes of their memory impairment, future losses resulting from the impairment, and the reactions of others (Werezak \& Stewart 2002). Fear and uncertainty may prompt them to plan how to manage the future (Keady \& Gilliard 2002). Neuropsychological testing may trigger or heighten feelings of threat, uncertainty, and anxiety (Burgener \& Dickerson-Putman 1999). This is especially the case if people receive little or no information about 
the testing or its consequences, forcing them to interpret these tests on their own (Keady \& Gilliard 2002). During the testing period, people may adopt several strategies to cope with perceived threats, such as taking time out, challenging the validity of a question, making excuses, avoiding awkward questions, relying on others for clarification and resisting. These strategies permit them to reflect on the test and the consequence of poor performance (Keady \& Gilliard 2002).

A diagnosis is made at the end of the diagnostic phase. In part, the diagnosis of dementia may be validating for the person, because it provides an explanation for their experiences and legitimizes the need to feel supported (Robinson et al. 1998, 2000a, 2000b, Pratt \& Wilkinson 2001). Withholding a diagnosis one wants to know causes distress (Pratt \& Wilkinson 2001). People unaware of their memory problems may become distressed when diagnosed with dementia, because the diagnosis forces them to acknowledge that their self-image does not match reality (Robinson et al. 2000a). Although the diagnosis may cause these people to re-evaluate their condition, they are often left with a vague and incomprehensible self-image, because the re-evaluation was prompted by others rather than themselves (Robinson et al. 2000a).

Despite providing validation, the diagnosis may threaten the person's sense of existence, resulting in fear of losing the ability to retain their personal identity in the future (Robinson et al. 1998). The diagnosis may cause shock, anger, fear, horror, depression and disbelief (Pratt \& Wilkinson 2001, Werezak \& Stewart 2002, Young 2002). Also, an early diagnosis may heighten awareness of personal limitations, which may restrict daily activities and reduce self-confidence (Pratt \& Wilkinson 2001).

Individuals experience some ambivalence when they receive their diagnosis, and this requires time to process (Snyder 2001). This processing time may explain in part a denial of the diagnosis; this type of denial is, of course, separate from that originating from organic cognitive impairment. Denial may provide enough time gradually to accept the painful truth; alternatively, it may indicate having difficulty in reconciling self-image with the devastating image of dementia (Snyder 2001). In addition, denial may arise from fear that acknowledging the disease will result in loss of autonomy (Snyder 2001). Difficulty in accepting the diagnosis also results when family members cover up the problems, either by denying that problems exist or by avoiding confrontation (Snyder 2001).

\section{Postdiagnostic phase}

Loss. Present or future losses may be considered by the individual after being diagnosed. Usually after an initial crisis period, they may also seek opportunities to move on with life in spite of the dementia (Robinson et al. 1998, Pratt \& Wilkinson 2001, Werezak \& Stewart 2002).

After accepting the prospect of living with dementia, people need to address several losses they experience, impaired cognition being one of the biggest. Table 2 lists several interrelated aspects of cognitive impairment that may be experienced. The meaning of these impairments becomes more apparent when considering their consequences. Loss of control is one prominent consequence that can affect many aspects of life, such as ability to act, which leads to feelings of incompetency (Harris \& Sterin 1999, Pearce et al. 2002, Young 2002, Clare 2003). Feeling incompetent may hinder a person in further engaging in meaningful tasks or taking on certain roles (Burgener \& Dickerson-Putman 1999, Pearce et al. 2002, Phinney 2002b, Young 2002, Clare 2003, Holst $\&$ Hallberg 2003).

Loss of meaningful activity may occur, along with loss of meaningful relationships, as opportunities to reach out to others are lost or others to retreat as incompetence develops (Nygard \& Borell 1998, Burgener \& Dickerson-Putman 1999, Harris \& Sterin 1999, Pearce et al. 2002, Holst \& Hallberg 2003). Loss of intimacy with the spouse (Burgener \& Dickerson-Putman 1999) or role changes in family relationships may be experienced, usually with a shift from

Table 2 Experiences commonly encountered with cognitive loss

Loss of thinking ability (Ostwald et al. 2002)

Decision-making difficulties (Pearce et al. 2002)

Problem-solving difficulties (Keady et al. 1995)

Loss of practical skills (Snyder 2001)

Needing more time to think to accomplish tasks (Phinney 2002b,

Phinney \& Chesla 2003)

Difficulty using objects or devices (Phinney 2002b, Phinney \& Chesla 2003)

Unable to perform or finish taken-for-granted tasks (without difficulty) (Keady et al. 1995, Nygard \& Borell 1998, Snyder

2001, Pearce et al. 2002, Phinney \& Chesla 2003)

Difficulties with new situations and activities (Nygard \& Borell 1998)

Forgetting/unable to recall names and events (Keady et al. 1995, Phinney 2002b)

Getting lost (Nygard et al. 1995, Phinney 1998, 2002b, Phinney \& Chesla 2003)

Losing things and spending time searching for them (Snyder 2001, Phinney 2002b)

Misperception or doubts about date or time that results in difficulty in keeping appointments (Nygard \& Borell 1998, Phinney 1998)

Losing track of conversations and having problems expressing oneself coherently (Phinney 1998, Burgener \& Dickerson-Putman 1999, Ostwald et al. 2002, Snyder 2002, Holst \& Hallberg 2003, Phinney \& Chesla 2003) 
an independent, equal standing to a dependent one (Snyder 2002, Svanstrom \& Dahlberg 2004).

As well as others taking control over their lives, dementia sufferers may also perceive a loss of control over reality (Keady et al. 1995, Nygard \& Borell 1998, Burgener \& Dickerson-Putman 1999, Ostwald et al. 2002). This can be due to auditory and visual hallucinations (Ostwald et al. 2002) but also to cognitive loss, which causes unpredictable 'gaps in the flow of their day-to-day lives' (Phinney 1998, p. 11) and a fluctuating awareness of symptoms (Phinney 1998, 2002a). Indeed, the person's world becomes an unpredictable and unfamiliar terrain (Phinney 1998, 2002b, Phinney \& Chesla 2003, Svanstrom \& Dahlberg 2004). Compounding this distorted reality is the discrepancy between personal perceptions and what others observe (Phinney 1998, 2002b, Ostwald et al. 2002). For those who are unaware of their memory problems, an additional burden can be difficulty in comprehending the disease, which may produce doubts about how to adjust and prepare for the future (Robinson et al. 2000a). Further difficulties with recalling parts of previous life may leave people with dementia with a sense of becoming a stranger in their own lives (Holst \& Hallberg 2003).

Losing control may result in loss of self-esteem and a changing sense of self (Harris \& Sterin 1999, Young 2002, Clare 2003, Holst \& Hallberg 2003). Core values associated with the self-identity are meaningful productivity, autonomy, comfort and security (Harris \& Sterin 1999). As a result of cognitive loss, these values are threatened in people with dementia, as is apparent in the experience of 'being slow' (Phinney \& Chesla 2003), 'being a blank' (Phinney \& Chesla 2003, Svanstrom \& Dahlberg 2004) and 'being lost' (Phinney \& Chesla 2003, Svanstrom \& Dahlberg 2004).

Feelings. Different feelings commonly accompany memory loss: irritation, frustration, uncertainty, or fear are frequently mentioned (Hutchinson et al. 1997, Burgener \& DickersonPutman 1999, Harris \& Sterin 1999, Ostwald et al. 2002, Phinney 2002b, Clare 2003, Holst \& Hallberg 2003). Even when people are well aware of their diagnosis, they commonly feel stressed, odd, confused, uncertain and insecure because of the incomprehensibility and unpredictability of their disease and its related changes (Robinson et al. 2000a, Pratt \& Wilkinson 2001, Ostwald et al. 2002, Phinney 2002b, Svanstrom \& Dahlberg 2004). They also fear embarrassing themselves and being humiliated (Gillies 2000, Phinney 2002b). A deflated sense of self-esteem becomes manifest through shame, guilt, uselessness, worthlessness, or stupidity (Nygard \& Borell 1998, Burgener \& Dickerson-Putman 1999, Harris \& Sterin 1999, Gillies 2000, Snyder 2001, Ostwald et al. 2002, Phinney 2002b, Clare
2003, Svanstrom \& Dahlberg 2004). These feelings may also be related to the stigma surrounding dementia (Hutchinson et al. 1997, Pratt \& Wilkinson 2001, Snyder 2001, 2002, Werezak \& Stewart 2002).

Feeling misunderstood, unsupported, unaccepted, or ignored by others (Werezak \& Stewart 2002, Clare 2003) may lead to feelings of alienation (Snyder 2002) and loneliness. Sadness and despair are also reported (Ostwald et al. 2002, Young 2002, Holst \& Hallberg 2003). Anger may arise from feelings of devaluation and being out of control (Keady et al. 1995, Hutchinson et al. 1997, Harris \& Sterin 1999, Snyder 2002, Holst \& Hallberg 2003). Anger and aggression may be displaced or focused on the self or others (Harris \& Sterin 1999, Young 2002, Holst \& Hallberg 2003).

These various feelings represent responses to both present and anticipated losses. Many worry about disease progression and a hopeless future (Pearce et al. 2002). As they anticipate the deterioration characteristic of dementia, sufferers fear losing the intellectual and social capacity that enables them to remain valued members of society; they fear becoming burdensome (Robinson et al. 2000a, Ostwald et al. 2002, Pearce et al. 2002, Snyder 2002, Werezak \& Stewart 2002, Clare 2003, Holst \& Hallberg 2003, Clare \& Shakespeare 2004); and they fear being abandoned (Gillies 2000, Robinson et al. 2000a, Clare 2003). The fear of becoming a burden is very difficult to handle, because it creates much guilt in those with dementia, since they feel responsible for the suffering and disappointment of their caregivers (Gillies 2000, Robinson et al. 2000a).

Forgetfulness, however, is not always frightening (Phinney 2002b). Similarly, being a burden (Snyder 2002) or fearing stigma (Snyder 2001) is not always a matter of concern. Positive and negative feelings may occur simultaneously. For example, past experiences can cause the person to feel quite competent; at the same time, new problems may cause them to feel incompetent (Nygard et al. 1995). After living through a negative crisis, a person with dementia may acquire a more positive attitude (Harris \& Durkin 2002, Werezak \& Stewart 2002, Young 2002).

Moving on: alternating between self-maintenance and selfadjustment. In living with dementia, moving on means coping with the changes and threats that accompany the disease. People with dementia struggle to hold on to their identity; simultaneously, they try to adjust to the changes dementia produces (Nygard \& Borell 1998, Gillies 2000, Robinson et al. 2000a, Keady \& Gilliard 2001, Menne et al. 2002, Pearce et al. 2002, Werezak \& Stewart 2002, Young 2002, Holst \& Hallberg 2003). The self-mainte- 
Table 3 Examples of self-protective and integrative strategies

\begin{tabular}{ll}
\hline Self-protective strategies & Integrative strategies \\
\hline
\end{tabular}

Expressing uncertainty about the possible severe nature of registered memory difficulties (Clare 2002)

Denial of problems (Gillies 2000, Ostwald et al. 2002)

Minimizing problems (Phinney 1998, Clare 2002, Pearce et al. 2002, Clare \& Shakespeare 2004)

Normalizing perceived changes (Gillies 2000, Clare 2002, Pearce et al. 2002, Clare \& Shakespeare 2004)

Focusing on continued ability to cope and lead a normal life (Nygard et al. 1995, Nygard \& Borell 1998, Pearce et al. 2002, Clare 2003)

Not pondering about one's memory deficits (Pearce et al. 2002, Young 2002, Clare 2003)

Focusing on contentment with the way life was going (Clare 2003, Clare \& Shakespeare 2004)

Adopting a fatalistic attitude (Clare 2003)

Becoming argumentative and defensive (Snyder 2002)

Trying harder to work or to perform at previous standard (Clare 2002, Pearce et al. 2002)

Staying engaged and keeping an active mind (Keady et al. 1995, Phinney 1998, Ostwald et al. 2002, Phinney 2002b)

Sticking to or setting up a routine (Keady et al. 1995, Keady \& Nolan 1995, Clare 2002, Pearce et al. 2002)

Maintaining hope (Clare 2002, Werezak \& Stewart 2002)

Using medication (Clare 2002, Pearce et al. 2002, Young 2002)

Self-monitoring (Phinney 1998)

Relying on partner or seeking support (Harris \& Sterin 1999, Gillies 2000, Robinson et al. 2000a, Ostwald et al. 2002, Pearce et al. 2002, Phinney 2002b, Werezak \& Stewart 2002, Clare 2003)

Using external memory aids such as calendars, lists, notes, etc. (Keady et al. 1995, Harris \& Sterin 1999, Gillies 2000, Clare 2002)

Avoiding activities (Burgener \& Dickerson-Putman 1999, Gillies 2000, Snyder 2002)

Isolating oneself from others (Ostwald et al. 2002, Snyder 2002, Werezak \& Stewart 2002)

Use of humour to mask inability to remember or respond appropriately (Burgener \& Dickerson-Putman 1999)
Adopting an attitude of making the best of a bad situation (Keady et al. 1995, Harris \& Sterin 1999, Clare 2002, Clare 2003)

Finding out more about dementia (Nygard \& Borell 1998, Clare 2002, Werezak \& Stewart 2002, Young 2002)

Talking about one's memory deficits (Clare 2002, Harris \& Durkin 2002, Ostwald et al. 2002, Werezak \& Stewart 2002)

Being useful in society (Clare 2002, Harris \& Durkin 2002, Menne et al. 2002, Ostwald et al. 2002)

Relinquishing unable-to-perform roles and replacing them with new or adapted roles (Harris \& Durkin 2002)

Focusing on good things (Clare 2002)

Attending support groups (Keady et al. 1995, Harris \& Sterin 1999, Snyder 2002, Young 2002)

Comparing oneself to others who are worse off (Clare 2002)

Using humour (Harris \& Sterin 1999, Werezak \& Stewart 2002)

Engaging in holistic practices and spiritual activities (Harris \& Durkin 2002)

Using innovative techniques and technology (Harris \& Durkin 2002)

Taking a proactive stance (Harris \& Durkin 2002)

Anticipating and preparing for future needs (Harris \& Durkin 2002) nance stance includes self-protective strategies, while the self-adjusting stance includes integrative strategies (Clare 2002).

Self-protective strategies (Table 3) aim to protect an individual's identity and to maintain normality and continuity in line with their identity before the onset of dementia (Phinney 1998, Clare 2003). As with the prediagnostic phase, protective strategies may be insufficient, forcing adoption of a self-adjustment stance to face difficulties, either by fighting or accepting them (Pearce et al. 2002). In this stance, integrative strategies are used (Table 3 ). When people openly confront the threats of dementia with the aim of dealing with them, sometimes despair results. Therefore, to come to terms with living with dementia, it is important for them to balance despair with hope and struggle with acceptance (Clare 2002).
Although adjusting is difficult for most people, especially soon after diagnosis, some are able to adjust successfully (Harris \& Sterin 1999, Pratt \& Wilkinson 2001, Werezak \& Stewart 2002, Young 2002). However, others keep struggling, predisposing them to severe depression (Werezak \& Stewart 2002, Young 2002). Harris and Sterin (1999) identified five reaction patterns that are characterized by (1) a strong and positive fighting spirit; (2) acquiescence without much struggle; (3) denial because of unacceptability; (4) an arduous and hardly successful struggle and (5) giving up the fight and thus losing a sense of continuity.

Acceptance may stem from a positive attitude (Harris \& Durkin 2002) or from resignation (Harris \& Sterin 1999, Gillies 2000, Robinson et al. 2000a). Accepting loss may relieve pressure (Snyder 2002, Holst \& Hallberg 2003) and 
permit an individual to focus on enjoying the remainder of life (Keady et al. 1995, Robinson et al. 2000a, Werezak \& Stewart 2002). By accepting their condition, these people 'reprioritize' the dementia so that it comprises only a part of their identity (Pratt \& Wilkinson 2001). However, acceptance is not always accomplished; nor is it always permanent once accomplished. Assimilation or 'fitting the dementia into one's life' (Werezak \& Stewart 2002 p. 77) is a cyclical and continuous process (Pratt \& Wilkinson 2001, Pearce et al. 2002, Werezak \& Stewart 2002, Clare 2003).

\section{Importance of social interaction}

Throughout the transitional process involved in coping with the diagnosis of dementia, the important role of social interaction in supporting or obstructing the quest to cope positively is evident. People commonly view the following as supportive: having a sense of belonging and being loved (Robinson et al. 2000a); of being understood, accepted and valued as an individual (Keady et al. 1995, Burgener \& Dickerson-Putman 1999, Robinson et al. 2000a, Snyder 2002, Werezak \& Stewart 2002, Holst \& Hallberg 2003); of being included in enjoyable and meaningful activities (Burgener \& Dickerson-Putman 1999, Robinson et al. 2000a, Snyder 2002, Werezak \& Stewart 2002) and of feeling supported (Robinson et al. 2000a, Pratt \& Wilkinson 2001, Werezak \& Stewart 2002). Because people experiencing early-stage dementia have an increased need to be comforted and to feel secure and valued, empathetic caregivers are needed to fulfil this burgeoning need. Caregivers are also needed because these people require added help in daily living; however, in having to rely on others, they may be forced to face their memory loss (Robinson et al. 2000a, Pearce et al. 2002, Phinney 2002 b). In response, they may retreat from others, physically or mentally, thus 'suffering in silence' (Robinson et al. 1997, p. 107).

Suffering in silence may serve different purposes. People may need time to adjust to their memory loss, to regroup and build up inner strength to endure, and to conceal problems and maintain an appearance of normality (Keady \& Gilliard 2001). They may also retreat to bolster their self-confidence and so as not to be reminded of their disease (Phinney 2002 b). Alternatively, some may choose to suffer in silence to protect themselves from the accusations of those who point to their forgetfulness; this mode of protection prevents such individuals from seeking help to understand their plight better or to move forward (Robinson et al. 2000a). Sufferers may also hide their problems out of a sense of responsibility for the consequences of their forgetfulness and to protect others (Keady et al. 1995, Hutchinson et al. 1997, Robinson et al. 2000a).

Hiding memory problems may strain relationships with family caregivers. These are already strained because all parties involved are adjusting to living with dementia (Snyder 2002, Svanstrom \& Dahlberg 2004). Sharing awareness before and after receiving the diagnosis of dementia and working together during the transitional period of adjustment may strengthen relationships (Young 2002, Keady \& Nolan 2003). Denial of the diagnosis by one or both parties in order to protect all involved causes the person with dementia and the caregiver to work independently, may eventually damage the relationship (Hutchinson et al. 1997, Young 2002, Clare 2003, Keady \& Nolan 2003, Clare \& Shakespeare 2004). Family members may refuse to participate in concealing the problems, or they may prevent the person from voicing their concerns (Clare \& Shakespeare 2004). In this way, the person may be silenced.

Interactions with professional caregivers may also silence the person with dementia and sometimes also family members (Young 2002). This is especially true if sufferers perceive that they are not taken seriously or are ignored or treated like children (Pratt \& Wilkinson 2001, Young 2002, Holst \& Hallberg 2003, Keady \& Nolan 2003), which may leave them with the feeling that they must deal with the dementia on their own. On the other hand, receiving appropriate concern and care from professional caregivers may encourage all parties, strengthening their resolve to work together (Keady \& Nolan 2003).

Being taken seriously and supported also plays a central role in enabling people with dementia to describe their impressions of living with dementia. However, fluctuating disease symptoms and varying awareness of these symptoms makes it difficult for the person with dementia to fully comprehend and relate their story. Because of this difficulty, both family and professional caregivers should look for ways beyond words to learn about the experience and to help tell the story (Phinney 2002a).

\section{Discussion}

In this review, we integrated findings from various studies to give an overview of the transitional processes experienced by those with early-stage dementia. However, the review was mainly based on cross-sectional studies that collected information retrospectively or focused on only one aspect of dementia or one time period. Only two studies had a longitudinal design (Nygard \& Borell 1998, Robinson et al. 2000a), of which only one covered the pre- and postdiag- 
nostic phases (Robinson et al. 2000a). More longitudinal research is necessary to explore important changes that are experienced during early-stage dementia and to examine the triggers and consequences of these changes.

Our review is limited to a meta-synthesis of qualitative studies. A synthesis of quantitative research findings concerning quality of life issues for people with early-stage dementia might provide valuable complementary information to enhance our understanding of important aspects of life with dementia.

As reflected by our assessment, living with early-stage dementia is a highly individualized experience wrought with diverse feelings and reactions. Although our findings contribute to formulating supportive care for these people, studying patient experiences can give us insight only into the possible course of dementia over time and do not allow us to predict what will happen in individual cases.

In line with Kitwood's (1990) concept of dementia as a socially-embedded phenomenon, we found several factors that influence the experience of living with dementia, two of which (unawareness and interaction with family and professional caregivers) were clearly apparent in our review. The influence of other factors, such as gender, age, personality, type of dementia, type of relationship with family caregivers, and educational level, remain unclear. In future research, people with diverse backgrounds should be examined to determine the influences of these factors on the experiences of living with dementia.

We identified certain features that corresponded across the 21 samples we examined, indicating that our review is, to some extent, generalizable to a larger population of people with dementia. These features include the experience of uncertainty; the importance of autonomy, meaningfulness, and security; and the struggle between self-protection and self-adjustment. All of these samples represent individuals willing to communicate their experiences. Whether these individuals also represent the voices of those unable or unwilling to relate their experiences remains to be determined.

The goal of this integrative review was to provide a better understanding of what it means to live with earlystage dementia. After a thorough literature search, we compared pertinent findings from different studies and formulated a description of living with early-stage dementia. This included a transitional process, starting with the prediagnostic phase, then the diagnostic phase and finally ending with the postdiagnostic phase. In general, the person with dementia is actively involved in this transitional process, noticing changes, searching for meaning, figuring out how to deal with current and future changes, and dealing with them. Integration of dementia into daily life is often carried out in silence, giving sufferers the time to think things through, to conceal problems, and to prevent losing face.

Memory decline often causes loss in many domains of life, including one's identity. Being a meaningful member of society, feeling secure, and having autonomy are threatened. The threat stems not only from the cognitive loss, but foremost from being accused, restricted, ignored, or patronized by others. For those unaware of their memory loss, the hard-to-comprehend reactions of others represent the forefront of their experience.

Family members also must adjust to the cognitive loss of their loved ones. How they cope may either help or hinder the affected person to deal successfully with dementia. The way in which professional caregivers interact with people with dementia and their families also can help or hinder efforts to deal with dementia. At present, the importance of this interaction during early stages of the disease has only been superficially touched on. Nurses and other professional caregivers should be made more aware of their potential to positively support those with dementia and their families. Additional research is needed to determine effective ways for professional caregivers to become skilled companions, so that all involved can work effectively to live with this disorder.

The efforts of professional and family caregivers to empathize with people with dementia can be hampered by various factors, such as denial. Memory difficulties, and especially varying awareness of these difficulties, may make it difficult for those with dementia to cope effectively, causing them to become frustrated, uncertain and fearful. Rather than counterbalancing despair with hope, many purposefully use denial to deal with perceived threats. In order for caregivers to provide the best possible care, they must listen carefully to these individuals, help them to understand the disease and its consequences, and look for ways to help them face threats positively.

Although at first a diagnosis of dementia may be devastating, in time it may become, for some, more of a challenge than a threat. With a varying degree of success, dementia can be integrated into the life of the person with dementia and their family and can be dealt with more positively. Yet, integration is a cyclical process. Due to the progressive nature of dementia, new difficulties may arise that cause all involved to reassess the situation (e.g. noticing changes, searching for their meaning and reacting accordingly). These setbacks commonly experienced by those with early-stage dementia support the need to develop proactive care with regular follow-up.

This review was founded on the belief that accurate knowledge of the lived experiences of people with early-stage 


\section{What is already known about this topic}

- Even in an early stage, dementia is disabling and may affect quality of life.

- Dementia is lived as a socially-embedded phenomenon, and knowledge of this lived experience is important in order to focus proactive care towards enhancing quality of life.

- Most studies on the experience of living with dementia at an early-stage are cross-sectional in nature.

\section{What this paper adds}

- Individuals with early-stage dementia experience a transitional process that starts with the sensation that something is wrong and extends to the integration of the disorder into their lives.

- Common features in the experience of living with earlystage dementia are feelings of uncertainty; the importance of autonomy, meaningfulness and security; and the struggle between self-protection and self-adjustment.

- Nurses have an important role in positively supporting people with dementia and their families from early on in the disease course.

dementia is central to developing effective proactive care for them. Successful proactive care programmes must acknowledge the importance of involving them as active and dignified participants in their own care. In addition, because both dementia sufferers and their families must adjust together to cope, professional caregivers must consider their concerns seriously. This means that proactive care should ensure that the diagnostic phase is performed respectfully, in a way that is tailored to how the parties involved are adjusting to the disorder, and with the aim of supporting them as they continue to adapt to their ever-changing circumstances. This may include boosting their self-esteem without disguising problems and providing hope, as appropriate.

\section{Conclusion}

This integrative review represents a synthesis of current qualitative research studies on the experience of living with dementia from the first-hand perspective of those with this disorder. These combined data reveal that people with earlystage dementia experience a transitional process, which starts with the sensation that something is wrong and extends to the integration of the disorder into their lives. During the latter, they develop strategies to preserve their self-identity and to adjust to their situation. Although more research is needed to refine and deepen our present understanding of living with dementia, this review emphasizes the need to develop proactive supportive care for these people and their families.

\section{Author contributions}

ES, BD, JG and MG were responsible for the study conception and design and drafting of the manuscript. ES performed the data collection and data analysis. BD, JG and MG made critical revisions to the paper. BD, JG and MG supervised the study.

\section{References}

Aggarwal N., Vass A., Minardi H., Ward R., Garfield C. \& Cybyk B. (2003) People with dementia and their relatives: personal experiences with Alzheimer's and of the provision of care. Journal of Psychiatric and Mental Health Nursing 10, 187-197.

American Psychiatric Association (1987) Diagnostic criteria for dementia. In Diagnostic and Statistical Manual of Mental Disorders, 3rd edn, revised. The American Psychiatric Association, Washington, p. 107.

Beattie A., Daker-White G., Gilliard J. \& Means R. (2004) 'How can they tell?' A qualitative study of the views of younger people about their dementia and dementia care services. Health and Social Care in the Community 12(4), 359-368.

Benner P. (1994) The tradition and skill of interpretive phenomenology in studying health, illness and caring practices. In Interpretive Phenomenology: Embodiment, Caring and Ethics in Health and Illness (Benner P., ed.), Sage Publications, Thousand Oaks, CA, pp. 99-127.

Benner P., Tanner C. \& Chesla C. (1996) Expertise in Nursing Practice: Caring, Clinical Judgment, and Ethics. Springer, New York, pp. 1-411.

Burgener S. \& Dickerson-Putman J. (1999) Assessing patients in the early stages of irreversible dementia: the relevance of patient perspectives. Journal of Gerontological Nursing 25(2), 33-41.

Burns N. (1989) Standards for qualitative research. Nursing Science Quarterly 2(1), 44-52.

Clare L. (2002) We'll fight it as long as we can: coping with the onset of Alzheimer's disease. Aging and Mental Health 6(2), 139-148.

Clare L. (2003) Managing threats to self: awareness in early stage Alzheimer's disease. Social Science and Medicine 5, 1017-1029.

Clare L. \& Shakespeare P. (2004) Negotiating the impact of forgetting: dimensions of resistance in task-oriented conversations between people with early-stage dementia and their partners. Dementia 3(2), 211-232.

Dabbs C. (1999) What do people with dementia most value in life. Journal of Dementia Care July/August, 16-19.

Dahlberg K., Drew N. \& Nyström M. (2001) Reflective Lifeworld Research. Studentenlitteratur, Lund, Sweden.

Diagnostic and Statistical Manual of Mental Disorders, DSM III-R (1987) Diagnostic and Statistical Manual of Mental Disorders, DSM III-R. The American Psychiatric Association, Washington. 
Eakin J.M. \& Mykhalovskiy E. (2003) Reframing the evaluation of qualitative health research: reflections on a review of appraisal guidelines in the health sciences. Journal of Evaluation in Clinical Practice 9(2), 187-194.

Evans D. (2003) Systematic reviews of interpretative research: interpretative data synthesis of processed data. Australian Journal of Advanced Nursing 20, 22-26.

Fingeld D. (2003) Metasynthesis: the state of the art - so far. Qualitative Health Research 13, 893-904.

Gillies B. (2000) A memory like clockwork: accounts of living through dementia. Aging and Mental Health 4(4), 366374.

Glaser B. \& Strauss A. (1965) Awareness of Dying. Aldine, New York, pp. 1-305.

Glaser B. \& Strauss A. (1967) The Discovery of Grounded Theory. Aldine, Chicago, pp. 1-271.

Grypdonck M. (1996) Het leven boven de ziekte uittillen. Spruyt, Van Mantgem, \& De Does, Leiden, The Netherlands.

Harris P. (ed.) (2002) The Person with Alzheimer's Disease: Pathways to Understanding the Experience. The Johns Hopkins University Press, Baltimore, pp. 1-289.

Harris P. \& Durkin C. (2002) Building resilience through coping and adapting. In The person with Alzheimer's disease: Pathways to Understanding the Experience (Harris P., ed.), The Johns Hopkins University Press, Baltimore, pp. 165-184.

Harris P. \& Sterin G. (1999) Insider's perspective: defining and preserving the self of dementia. Journal of Mental Health and Aging 5(3), 241-256.

Holst G. \& Hallberg I. (2003) Exploring the meaning of everyday life, for those suffering from dementia. American Journal of Alzheimer's Disease and Other Dementias 18(6), 359-365.

Husband H. (2000) Diagnostic disclosure in dementia: an opportunity for intervention? International Journal of Geriatric Psychiatry $15,544-547$.

Hutchinson S., Leger-Krall S. \& Skodol Wilson H. (1997) Early probable Alzheimer's disease and Awareness Context Theory. Social Science and Medicine 45(9), 1399-1409.

Keady J. \& Gilliard J. (2001) The early experience of Alzheimer's disease: implications for partnership and practice. In Dementia Care: Developing Partnerships in Practice (Adams T. \& Clarke C., eds), Ballière Tindall, London, pp. 227-256.

Keady J. \& Gilliard J. (2002) Testing times: the experience of neuropsychological assessment for people with suspected Alzheimer's. In The Person with Alzheimer's Disease: Pathways to Understanding the Experience (Harris P., ed.), The Johns Hopkins University Press, Baltimore, pp. 3-28.

Keady J. \& Nolan M. (1995) IMMEL 2: working to augment coping responses in early dementia. British Journal of Nursing 4(7), 377380.

Keady J. \& Nolan M. (2003) The dynamics of dementia: working together, working separately, or working alone? In Partnership in Family Care (Nolan M., Lundh U., Grant G. \& Keady J., eds), Open University Press, Buckingham, pp. 15-32.

Keady J., Nolan M. \& Gilliard J. (1995) Listen to the voices of experience. Journal of Dementia Care May/June, 15-17.

Keady J., Gilliard J., Evers C. \& Milton S. (1999a) The DIAL-log study 1: profiling the experience of people with dementia. British Journal of Nursing 8(6), 387-393.
Keady J., Gilliard J., Evers C. \& Milton S. (1999b) The DIAL-log Study 2: support in the early stages of dementia. British Journal of Nursing 8(7), 432-436.

Keady J., Harris P. \& Wilkinson H. (eds) (2002) Dementia: The International Journal of Social Research and Practice. February 2002-October 2004. Sage Publications, London.

Kitwood T. (1990) The dialectics of dementia: with particular reference to Alzheimer's disease. Ageing and Society 10, 177-196.

Lyman K. (1989) Bringing the social back in: a critique of the biomedicalization of dementia. The Gerontologist 29(5), 597-605.

van Manen M. (1990) Researching Lived Experience: Human Science for an Action Sensitive Pedagogy. Althouse Press, London, pp. 1-202.

Marzanski M. (2000) Would you like to know what is wrong with you. On telling the truth to patients with dementia? Journal of Medical Ethics 26, 108-113.

Menne H., Kinney J. \& Morhardt D. (2002) 'Trying to continue to do as much as they can do': theoretical insights regarding continuity and meaning making in the face of dementia. Dementia 1(3), 367-382.

Miles M.B. \& Huberman A.M. (1994) Qualitative Data Analysis: An Extended Source Book, 1st edn. Sage, Thousand Oaks, CA, pp. 1338.

Nesbit K. (s.a.) Evidence Based Filters for Ovid CINHAL. Edward G. Miner Library, University of Rochester Medical Center. Retrieved from http://www.urmc.rochester.edu/hslt/miner/digital_ library/evidence_based_resources.cfm on 1 September 2004.

Norman I., Redfern S., Briggs K. \& Askham J. (2004) Perceptions and management of change by people with dementia and their carers living at home. Dementia 3(1), 19-44.

Nygard L. \& Borell L. (1998) A life-world of altering meaning: expressions of the illness experience of dementia in everyday life over 3 years. Occupational Therapy Journal of Research 18(3), 109136.

Nygard L., Borell L. \& Gustavsson A. (1995) Managing images of occupational self in early stage dementia. Scandinavian Journal of Occupational Therapy 2, 129-137.

Ostwald S.K., Duggleby W. \& Hepburn K.W. (2002) The stress of dementia: view from the inside. American Journal of Alzheimer's Disease and Other Dementias 17(5), 303-312.

Parse R. (1996) Quality of life for persons living with Alzheimer's disease: the human becoming perspective. Nursing Science Quarterly 9(3), 126-133.

Pearce A., Clare L. \& Pistrang N. (2002) Managing sense of self: coping in the early stages of Alzheimer's disease. Dementia 1(2), 173-192.

Phinney A. (1998) Living with dementia from the patient's perspective. Journal of Gerontological Nursing 24(6), 8-15.

Phinney A. (2002a) Fluctuating awareness and the breakdown of the illness narrative in dementia. Dementia 1(3), 329-344.

Phinney A. (2002b) Living with the symptoms of Alzheimer's disease. In The Person with Alzheimer's Disease: Pathways to Understanding the Experience (Harris P., ed.), The Johns Hopkins University Press, Baltimore, pp. 49-74.

Phinney A. \& Chesla C. (2003) The lived body in dementia. Journal of Aging Studies 17, 283-299.

Popay J., Rogers A. \& Williams G. (1998) Rationale and standards for the systematic review of qualitative literature in 
health services research. Qualitative Health Research 8(3), 341351.

Pratt R. \& Wilkinson H. (2001) 'Tell me the Truth': The Effect of Being Told the Diagnosis of Dementia from the Perspective of the Person with Dementia. The Mental Health Foundation, London, pp. 1-39.

Proctor G. (2001) Listening to older women with dementia: relationships, voices and power. Disability and Society 16(3), 361376.

Reid D., Ryan T. \& Enderby P. (2001) What does it mean to listen to people with dementia? Disability and Society 16(3), 377-392.

Robinson P. (2000) Younger Persons with Suspected and Early Stage Dementia: Their Experiences, Concerns and Need for Support. Department of Clinical Neuroscience, Occupational Therapy and Elderly Care Research, Division of Geriatric Medicine, Karolinska Institute, Stockholm, Sweden, pp. 1-50.

Robinson P., Ekman S.-L., Meleis I., Winblad B. \& Wahlund L.-O. (1997) Suffering in silence: the experience of early memory loss. Health Care in Later Life 2(2), 107-120.

Robinson P., Ekman S.-L. \& Wahlund L.-O. (1998) Unsettled, uncertain and striving to understand: toward an understanding of the situation of persons with suspected dementia. International Journal of Aging and Human Development 47(2), 143161.

Robinson P., Giorgi B., Ekman S.-L. \& Wahlund L.-O. (2000a) The experience of early dementia: a three-year longitudinal phenomenological case study. In Younger Persons with Suspected and Early Stage Dementia: Their Experiences, Concerns and Need for Support (Robinson P., ed.), Department of Clinical Neuroscience, Occupational Therapy and Elderly Care Research, Division of Geriatric Medicine, Karolinska Institute, Stockholm, Sweden, Appendix III, pp. 1-33.

Robinson P., Wahlund L.-O. \& Ekman S.-L. (2000b) Is it dementia? Patients' understanding of and responses to a clinical diagnosis. In Younger Persons with Suspected and Early Stage Dementia: Their Experiences, Concerns and Need for Support (Robinson P., ed.), Department of Clinical Neuroscience, Occupational Therapy and Elderly Care Research, Division of Geriatric Medicine, Karolinska Institute, Stockholm, Sweden, Appendix II, pp. 1-21.

Sandelowski M. \& Barosso J. (2002) Reading qualitative studies. International Journal of Qualitative Methods 1(1), 1-47. Article 5. Retrieved from http://www.ualberta.ca/ ijqm/ on 1 September 2004.

Sherwood G. (1999) Meta-synthesis: merging qualitative studies to develop nursing knowledge. International Journal for Human Caring 3(1), 37-42.

Snyder L. (2001) The lived experience of Alzheimer's: understanding the feelings and subjective accounts of persons with the disease. Alzheimer's Care Quarterly 2(2), 8-22.

Snyder L. (2002) Social and family relationships: establishing and maintaining connections. In The Person with Alzheimer's Disease: Pathways to Understanding the Experience (Harris P., ed.), The Johns Hopkins University Press, Baltimore, pp. 112-133.

Strauss A. (1987) Qualitative Analysis for Social Scientists. Cambridge University Press, Cambridge MA, pp. 1-319.

Svanstrom R. \& Dahlberg K. (2004) Living with dementia yields a heteronomous and lost existence. Western Journal of Nursing Research 26(6), 671-687.

World Health Organization (1993) The ICD-10 Classification of Mental and Behavioural Disorders: Diagnostic Criteria for Research. WHO, Geneva.

Werezak L. \& Stewart N. (2002) Learning to live with early dementia. The Canadian Journal of Nursing Research 34(1), 6785.

Young R. (2002) Medical experiences and concerns of people with Alzheimer's disease. In The Person with Alzheimer's Disease: Pathway to Understanding the Experience (Harris P., ed.), The Johns Hopkins University Press, Baltimore, pp. 29-46. 